\title{
Chave de identificação dos hidróides (Cnidaria, Hydrozoa) epifíticos do Canal de São Sebastião (SE, Brasil)
}

\author{
Otto Müller Patrão de Oliveira ${ }^{2,3}$, Antonio Carlos Marques $^{2}$ \& Alvaro Esteves Migotto ${ }^{1}$
}

Biota Neotropica v6 (n2) - http://www.biotaneotropica.org.br/v6n2/pt/abstract?identification-key+bn02306022006

Recebido em 03/05/2005.

Versão reformulada em 15/03/2006.

Aceito e publicado em 11/05/2006.

${ }^{1}$ Centro de Biologia Marinha, Universidade de São Paulo, Rodovia Manoel H. do Rego km 131,5, 11600-000

São Sebastião, SP, Brasil - www.usp.br/cbm

${ }^{2}$ Departamento de Zoologia, Instituto de Biociências, Universidade de São Paulo, Caixa Postal 11461, 05422-970

São Paulo, SP, Brasil - www.ib.usp.br

${ }^{3}$ Autor para correspondência: O.M.P.Oliveira (e-mail: ottompo@usp.br)

\begin{abstract}
Oliveira, O. M. P.; Marques, A. C. and Migotto, A. E. Identification key for the epiphytic hydroids (Cnidaria, Hydrozoa) from the São Sebastião Channel (SE Brazil). Biota Neotrop. May/Aug 2006 vol. 6 no. 2, http:// www.biotaneotropica.org.br/v6n2/pt/abstract?identification-key+bn02306022006. ISSN 1676-0603
\end{abstract}

The present study is a taxonomic key for epiphytic hydroids from the São Sebastião channel. It aims to help students and non-specialist researchers with the identification of those hydrozoans associated with vegetal substrata. Methods for hydroid preservation and slides preparation are described. Characters that distinguish the 36 species are presented.

Key words: epiphytism, benthos, hydrozoans

\section{Resumo}

Oliveira, O. M. P.; Marques, A. C. and Migotto, A. E. Chave de identificação dos hidróides (Cnidaria, Hydrozoa) epifíticos do Canal de São Sebastião (SE, Brasil). Biota Neotrop. May/Aug 2006 vol. 6 no. 2, http://www.biotaneotropica.org.br/ v6n2/pt/abstract?identification-key+bn02306022006. ISSN 1676-0603

O presente estudo tem por objetivo auxiliar pesquisadores pouco familiarizados com a taxonomia e a identificação dos hidrozoários bentônicos, especialmente das espécies que ocorrem sobre substrato vegetal em ambiente marinho, tomando a fauna do Canal de São Sebastião como modelo. Métodos para a fixação dos hidróides e a confecção de lâminas para identificação, além de características que distinguem 36 espécies epifíticas são descritas no texto.

Palavras-chave: epifitismo, bentos, hidrozoários 


\section{Introdução}

Os hidróides são cnidários pertencentes às subclasses Anthoathecata e Leptothecata, duas das oito subclasses da classe Hydrozoa (as demais são Actinulida, Laingiomedusae, Limnomedusae, Narcomedusae, Siphonophorae e Trachymedusae, $c f$. Marques \& Collins 2004, van Iten et al. 2006; Collins et al 2006, consideram os Laingiomedusae incluídos nos Anthoathecata). Os Leptothecata são mais conhecidos como "tecados", devido à existência de uma hidroteca rígida que envolve e protege o hidrante. A hidroteca é uma estrutura ausente nos Anthoathecata, que por essa razão são denominados de "atecados". Os ciclos de vida de ambos os grupos são caracterizados basicamente pela presença de dois estágios morfológica e ecologicamente distintos, o pólipo (geralmente bentônico e séssil, individuais ou coloniais), e a medusa (geralmente planctônica e livre-natante). Os pólipos reproduzem-se assexuadamente formando colônias ou novos pólipos individuais, bem como medusas por brotamento lateral. As medusas, geralmente de sexos separados, são responsáveis pela reprodução sexuada. Neste tipo de reprodução, os ovos desenvolvemse em larvas plânulas que, ao assentarem, originam novamente indivíduos polipóides. Variações desse ciclo básico são bastante comuns entre as espécies de hidróides, com a redução em diversos graus tanto da fase de pólipo como da de medusa.

A morfologia desses grupos parece ser, a princípio, simples. De organização tecidual pouco complexa, constituída de epiderme e gastroderme celulares e uma camada acelular de mesogléia, os pólipos e colônias dos hidróides exibem formas e morfologias bastante variadas. Suas características básicas são, todavia, facilmente reconhecíveis (Figura 1).

A identificação de hidróides consiste na averiguação e medição de características morfológicas do perissarco, especialmente no caso dos hidróides tecados, e do hidrante (Figura 1), além do exame das estruturas da colônia, de aspectos reprodutivos e do cnidoma (Millard 1975). Devido à plasticidade adaptativa destes animais, com variações morfológicas significativas em diferentes condições ambientais, e do número relativamente baixo de caracteres utilizáveis na taxonomia, uma identificação segura implica na observação e mensuração do maior número possível de características (e.g. Silveira \& Migotto 1991, Lindner 2000, Oliveira et al. 2000, Andrade 2001).
Os hidróides habitam praticamente todos os ambientes marinhos e são abundantes e ecologicamente diversos em algumas regiões (Gili \& Hughes 1995). Sobretudo marinhos, ocorrem também em água doce ou salobra, e podem ser encontrados da zona entremarés até profundidades abissais, geralmente fixados sobre substratos artificiais ou naturais de origem mineral, animal, vegetal ou, em casos particulares, como habitantes de substratos não consolidados, inclusive como parte da fauna psâmica (Gili \& Hughes 1995). No ecossistema fital, os hidróides estão entre os principais grupos que utilizam as plantas como substrato, competindo espacialmente com, por exemplo, poríferos, briozoários e tunicados (cf. Masunari \& Forneris 1981).

O conhecimento da fauna de hidrozoários bentônicos no canal de São Sebastião é relativamente bom (Migotto et al. 1999), devido à existência de levantamentos faunísticos (e.g., Migotto 1996) e de vários registros e descrições pontuais (e.g., Migotto \& Silveira 1987, Marques 1993, 1995, 2001, Migotto \& Marques 1999a, b, Lindner 2000, Lindner \& Migotto 2002, Marques \& Oliveira 2003). O estudo dos hidróides epifíticos dessa região (Oliveira 2003) possibilitou a elaboração de uma chave de identificação funcional voltada para um público não especialista ou iniciante no estudo de Hydrozoa, que necessite identificar rápida e preliminarmente os hidróides encontrados sobre macrófitas.

A presente chave não tem o objetivo de esgotar o assunto. Para uma identificação razoavelmente segura, é praticamente obrigatório recorrer simultaneamente à bibliografia especializada, incluindo trabalhos de cunho geral e faunístico (e.g., Millard 1975, Bouillon 1985, Calder 1988, 1991, 1997, Cornelius 1995, Migotto 1996, Marques 2001), assim como às descrições sistemáticas das espécies, particularmente daquelas com distribuição na região de estudo. Como existe a possibilidade do usuário encontrar uma espécie não abordada na chave, a consulta à literatura pertinente e a comparação com descrições detalhadas poderá evitar um possível erro de identificação.

\section{Material e Métodos}

Para garantir a obtenção de um bom material de estudo, do qual se possa retirar o maior número de informações, alguns procedimentos para a coleta e preparação dos hidróides epifíticos, apresentados a seguir, deverão ser adotados. 
A triagem das algas deve ser conduzida, preferencialmente, sob estereomicroscópio. Ao se detectar a presença de um hidróide, deve-se retirá-lo, juntamente com uma pequena porção da macrófita, com o auxílio de tesoura e pinça de ponta fina; somente as colônias relativamente grandes e robustas devem ser destacadas diretamente do substrato fital, tomando-se o cuidado de removê-las com pelo menos uma parte da estrutura de fixação (estolão ou hidrorriza). Uma vez isolado, o material deve ser anestesiado por poucos minutos em solução de cloreto de magnésio. Prepara-se a solução diluindo $75 \mathrm{~g}$ de $\mathrm{MgCl}_{2} 6 \mathrm{H}_{2} \mathrm{O}$ em um litro de água destilada, de forma a ficar isotônica com a água do mar. Tal solução é utilizada na proporção 1:1 com água do mar, visando o relaxamento das partes moles do corpo, o que facilita a observação das características do hidrante.

Os espécimes de hidróides devem ser fixados preferencialmente em solução salina de formol a $10 \%$, exceto nos estudos de biologia molecular, cujo fixador deve ser o etanol (preferencialmente a 95\%). Nesse último caso, espécimes testemunhos devem ser preservados em formol, devidamente etiquetados com dados de coleta, incluindo as coordenadas geográficas, tipo de substrato e profundidade, e depositados, preferencialmente, em coleções onde possam receber curadoria adequada. Sempre que possível, nas etiquetas devem constar a coloração do animal quando vivo e outros aspectos da biologia da espécie, como a observação da condição reprodutiva, a liberação de medusas ou plânulas etc.

A morfologia da hidroteca e gonoteca é importante na identificação de hidróides tecados, mas geralmente a presença de tecidos dificulta a observação de detalhes morfológicos dessas tecas. Nesse caso, o tratamento de pequenas partes da colônia, por alguns segundos ou minutos (tempo variável de acordo com o porte e a quantidade de tecido de cada espécime), em uma solução de hipoclorito de sódio, e a posterior lavagem em água destilada, promove a remoção do cenossarco, facilitando a observação de características do perissarco, como a forma e ornamentação das hidrotecas e gonotecas (figura 1).

As medições e o estudo da maior parte das características necessárias à identificação devem ser feitos sob microscópio óptico, por meio de montagens não permanentes, entre lâmina e lamínula, de pólipos ou fragmentos de colônias. A utilização de pequenas quantidades de massa de modelar (plasticina) nos vértices da lamínula confere estabilidade à preparação e permite o preenchimento do espaço entre lâmina e lamínula com água do mar, no caso de material vivo, ou água doce ou fixador, no caso do material preservado. Esse espaço pode ser facilmente ajustado pressionando-se delicadamente os cantos da lamínula, tomando-se o cuidado para não comprimir o espécime a ponto de deformá-lo. Técnicas para a preparação de lâminas permanentes também podem ser utilizadas (e.g. Mahoney 1973), embora demandem um maior esforço de preparação e nem sempre dêem bons resultados.

A determinação do cnidoma, ou seja, o estudo dos tipos, distribuição e dimensões dos nematocistos presentes nos tecidos dos hidrozoários, é importante na identificação de certos táxons. Para isso, são utilizados esfregaços de fragmentos de hidrantes ou de colônias em lâminas histológicas recobertas por lamínulas. O reconhecimento dos tipos morfológicos dos nematocistos é mais fácil se as preparações forem feitas com tecidos vivos. Nesse caso, a adição de água destilada ou saliva à preparação geralmente promove a explosão dos nematocistos, possibilitando a identificação do tipo a que pertencem (ver Mariscal 1974, Millard 1975). A medição dos nematocistos, quando necessária, deve ser feita a partir de materiais fixados; mede-se o comprimento e largura de cápsulas íntegras dos diversos tipos nematocistos que não se encontrem dispostas obliquamente na preparação.

Para aqueles que não possuem familiaridade com a nomenclatura utilizada no estudo de Hydrozoa, um glossário para os termos empregados neste estudo é apresentado após a chave (anexo 1). Os glossários de termos contidos em Migotto (1993 p.220-226), Millard (1975 p.6-20) e Cornelius (1995) também são de grande ajuda.

\section{Resultados e Discussão}

Para o presente estudo foram consideradas as 32 espécies coletadas para o estudo de Oliveira (2003), além de espécies complementares coletadas no estudo de Migotto (1996). No total foram consideradas 36 espécies (Tabela 1), sendo 27 pertencentes à ordem Leptothecata e as nove restantes à ordem Anthoathecata.

A seguir é apresentada a chave de identificação resultante deste estudo. 


\section{Chave de identificação para as espécies de hidróides epifíticos do Canal de São Sebastião.}

1a Hidróides sem hidroteca ou como uma fina e membranosa pseudo-hidroteca envolvendo o hidrante (Anthoathecata) 2

1b Hidróides com hidroteca (Leptothecata)

2a Hidróides com pelo menos alguns tentáculos capitados (Capitata)

2b Hidróides com tentáculos filiformes somente (Filifera)

3a Tentáculos dispersos ao redor do hidrante ou formando coroas irregulares (Zancleidae)

3b Tentáculos dispostos em coroas (oral e aboral)

4a Hidrante com tentáculos orais curtos e tentáculos aborais filiformes longos; gonóforos entre as coroas de tentáculos nas colônias maduras (Tubulariidae)

4b Hidrantes não como acima

5a Blastóstilos com gonóforos sésseis do tipo criptomedusóides, que originam diretamente actínulas; hidrocaule anelado

Pinauay ralphi (figura 5)

(vide Migotto \& Silveira 1987 p.101 figura 3, Marques \& Migotto 2001 figura 2b)

5b Blastóstilos originam medusas livres; hidrocaule liso

Ectopleura obypa (figura 4) (vide Migotto \& Marques 1999 p.304 figuras 1-3, Marques \& Migotto 2001 figura 1f)

6a Hidrante com duas ou mais coroas de tentáculos aborais ramificados e capitados (Cladocorynidae); hidrante de coloração geralmente avermelhada

Cladocoryne floccosa (figura 2) (vide Migotto 1996 p.17 figura 4a-b)

6b Hidrante com uma coroa de tentáculos aborais filiformes reduzidos (Cladonematidae); hidrante de coloração esbranquiçada

7a Tentáculos dispersos ao redor do hidrante, não dispostos em círculos nítidos (Clavidae)

7b Hidrantes com tentáculos dispostos em círculo(s) na extremidade distal

8a Perissarco incrustado por silte e detritos, formando uma pseudohidroteca que envolve o hidrante e a porção proximal dos tentáculos; hipostômio cônico (Bougainvillidae)

8b Perisssarco sem incrustações, pseudo-hidroteca ausente; hidrante com hipostômio em forma de trompete (Eudendriidae)

9a Perissarco do hidrocaule e dos ramos completa ou quase completamente anelados; blastóstilos femininos e masculinos com tentáculos quando maduros; hidrantes amarelados ou acastanhados, com nematocistos grandes do tipo euritelo microbásico 
9b Perissarco com anelações raras e espaçadas; blastóstilos femininos e masculinos com tentáculos totalmente reduzidos quando maduros; hidrantes de coloração esbranquiçada a avermelhada, sem nematocistos grandes do tipo euritelo microbásico

10a Hidroteca adnata ao hidrocaule

10b Hidroteca não adnata ao hidrocaule

11a Nematotecas ausentes

12a Hidroteca com anelações transversais (Sertulariidae)

12b Hidroteca lisa, sem anelações transversais

13a Hidroteca mais estreita na porção basal, alargando gradualmente em direção à margem; hidrante sem divertículo abcaulinar

13b Hidroteca não alargada na porção distal; hidrante com divertículo abcaulinar

15a Mais de um par de hidrotecas em alguns internódios

16a Hidroteca com 190-320 $\mu \mathrm{m}$ de comprimento; hidrante com divertículo abcaulinar

16b Hidroteca com 340-790 $\mu \mathrm{m}$ de comprimento; hidrante sem divertículo abcaulinar

17a Colônias em forma de pena, com hidrocládios alternados; internódios do ramo principal com três hidrotecas

17b Colônias sem hidrocládios; internódios com um par de hidrotecas 1998 figuras 1-2) opostas

18a Internódios divididos por nós pouco distintos, transversais; hidrante com lígula 
19a Nematoteca mesial adnata à hidroteca (Aglaopheniidae)

19b Nematoteca mesial não adnata à hidroteca

20a Colônias em forma de pena, monossifônicas; hidroteca com nove cúspides marginais; gonângios dentro de uma estrutura protetora (córbula)

20b Colônias ramificadas, polissifônicas; hidroteca com três cúspides laterais; gonângios ovais e comprimidos, protegidos por ramos Macrorhynchia philippina (figura especiais (filatocarpos)

(vide Migotto 1996 p.40 figura 8e-f, Calder 1997 p.66 figura 21)

21a Hidroteca sem nematotecas laterais (Kirchenpaueriidae)

21b Hidroteca com nematotecas laterais

22a Ramo principal do hidrocaule com hidrotecas (Halopterididae)

22b Ramo principal do hidrocaule sem hidrotecas (Plumulariidae)

23a Alternância entre internódios com e sem hidrotecas Halopteris diaphana (figura 17) (vide Migotto 1996 p.44 figura 9a-c como Halopteris constricta)

23b Todos os internódios com hidrotecas

24a Hidroteca tão larga quanto profunda; margens das nematotecas laterais não ultrapassam a margem da hidroteca; sem nematotecas axilares

(vide Migotto 1996 p.45 figura 9d-e como Halopteris diaphana, Calder 1997 p.36 figura 9)

24b Hidroteca mais profunda do que larga; margens das nematotecas laterais ultrapassam a margem da hidroteca; com uma ou duas nematotecas axilares (vide Migotto 1996 p.48 figura 9f-h como Halopteris buskii)

25a Apenas uma hidroteca por hidrocládio; hidroteca parcialmente adnata ao internódio; parede abcaulinar da hidroteca ligeiramente curvada

25b Hidrocládios com mais de uma hidroteca; hidroteca totalmente adnata ao internódio; parede abcaulinar da hidroteca reta

26a Hipostômio cônico; hidroteca não pedicelada, séssil e rasa, não comportando o hidrante retraído (Haleciidae)

26b Hipostômio esférico ou em forma de trompete (Proboscoida); hidroteca pedicelada, em forma de campânula ou taça, comportando o hidrante quando este se retrai (Campanulariidae)

27a Margem da hidroteca não evertida; hidroteca aproximadamente tão alta quanto larga; gonoteca surgindo de dentro de hidroteca 
27b Margem da hidroteca evertida; hidroteca acentuadamente mais larga do que alta; gonoteca não surgindo de dentro de uma hidroteca

28a Margem da hidroteca ligeiramente evertida; colônia mono ou polissifônica; gonoteca anelada, pode assumir a posição de um ramo, não surgindo diretamente da hidrorriza

Halecium dichotomum (figura 13) (vide Migotto 1996 p.31 figura 6f-g)

28b Margem da hidroteca evertida; colônia monossifônica; gonoteca surge diretamente da hidrorriza

Halecium tenellum (figura 15) (vide Calder 1991 p.22 figura 14, Migotto 1996 p.34 figura 6h)

29a Colônia de crescimento estolonal, com esférula sub-hidrotecal; hidroteca com ou sem diafragma

29b Colônia ereta ou estolonal, sem esférula sub-hidrotecal; hidroteca com diafragma

30a Hidroteca sem diafragma; pedículo com ondulações; margem Orthopyxis sargassicola (figura hidrotecal com cúspides

(vide Calder 1991 p.51 figura 30, Migotto 1996 p.91 figura 16f-i)

30b Hidroteca com diafragma oblíquo; pedículo parcialmente anelado; margem hidrotecal lisa

32a Margem da hidroteca com cúspides bifurcadas

32b Margem da hidroteca com cúspides simples, pontiagudas ou arredondadas

33a Margem da hidroteca com cúspides arredondadas

Clytia noliformis (figura 33) (vide Calder 1991 p.65 figura 36, Lindner \& Migotto 2002 p.546 figura 4)

33b Margem da hidroteca com cúspides agudas

34a Hidroteca contendo plicas que se estendem de sua margem cerca da metade do comprimento da hidroteca; cúspides retas

Clytia linearis (figura 32)

(vide Calder 1991 p.62 figura 34, Migotto 1996 p.85 figura 16a-b, Lindner \& Migotto 2002 p.542

figura 2)

34b Hidroteca sem plicas; cúspides inclinadas no sentido anti-horário em vista oral

35a Diafragma oblíquo; perissarco fino

Obelia dichotoma (figura 35) (vide Calder 1991 p.72 figura 38, Migotto 1996 p.88 figura 16d)

35b Diafragma transversal; perissarco dos internódios e da hidroteca espesso 


\section{Agradecimentos}

Agradecemos às colegas Júlia A. Gondra, Juliana E. Borges, Mariene M. Nomura e Thaís P. Miranda que testaram a chave; e a dois revisores anônimos, por suas considerações. Este estudo foi financiado com recursos da FAPESP (Proc. 2000/14932-2; 2001/02626-7; 2004/15300-0; 2004/09961-4) e CNPq (Proc. 300194/1994-3; 302596/2003-8; 471960/2004-7).

\section{Referências bibliográficas}

ANDRADE, L.P. 2001. Aspectos da biologia e do ciclo de vida de Aglaophenia latecarinata (Cnidaria, Hydrozoa, Aglaopheniidae). Dissertação de mestrado, Instituto de Biociências, Universidade de São Paulo, São Paulo.

BOUILLON, J. 1985. Essai de classification des Hydropolypes - Hydroméduses (Hydrozoa-Cnidaria). Indo-Malayan Zool. 2(1):29-243.

CALDER, D.R. 1988. Shallow-water hydroid of Bermuda: The Athecate. Life Sci. Contrs Roy. Ontario Mus. 148:1-107.

CALDER, D.R. 1991. Shallow-water hydroid of Bermuda: The Thecate, exclusive of Plumularioidea. Life Sci. Contrs Roy. Ontario Mus. 154:1-140.

CALDER, D.R. 1997. Shallow-water hydroid of Bermuda: Superfamily Plumularioidea. Life Sci. Contrs Roy. Ontario Mus. 161:1-107.

COLLINS, A.G., SCHUCHERT, P., MARQUES, A.C., JANKOWSKI, T., MEDINA, M. \& SCHIERWATER, B. 2006. Cnidarian phylogeny and character evolution clarified by new large and small subunit rDNA data and an assessment of the utility of phylogenetic mixture models. Syst. Biol. 55(1):97-115.

CORNELIUS, P.F.S. 1995. North-West European Thecate Hydroids and their Medusae. In Synopses of the British Fauna - New Series (R.K.S. Barnes \& J.H. Crothers, eds.). No.50, Part 1-2.

GILI, J.M. \& HUGHES, R.G. 1995. The ecology of marine benthic hydroids. Oceanogr. Mar. Biol. Annu. Rev. 33:351-426.

LINDNER, A. 2000. Redescrição do ciclo de vida de Clytia gracilis e Clytia linearis (Cnidaria, Hydrozoa, Campanulariidae). Dissertação de mestrado, Instituto de Biociências, Universidade de São Paulo, São Paulo.

LINDNER,A. \& MIGOTTO, A.E. 2002. The life cycle of Clytia linearis and Clytia noliformis: metagenic campanulariids (Cnidaria: Hydrozoa) with contrasting polyp and medusa stages. J. Mar. Biol. Ass. U. K. 82:541-553.

MAHONEY, R. 1973. Laboratory techniques in Zoology. Butterworth \& Co., London.

MARISCAL, R.N. 1974. Nematocysts. In Coelenterate Biology - Reviews and new perspectives (L. Muscatine \& H.M. Lenhoff, eds). Academic Press, New York. p.129-178.
MARQUES, A.C. 1993. Sistemática dos Eudendriidae L. Agassiz, 1862 (Cnidaria, Hydrozoa) do litoral paulista. Dissertação de mestrado, Instituto de Biociências, Universidade de São Paulo, São Paulo.

MARQUES, A.C. 1995. Eudendrium pocaruquarum n. sp. (Hydrozoa, Eudendriidae) from the southeastern coast of Brazil, with remarks on taxonomic approaches to the family Eudendriidae. Contrib. Zool. 65(1):35-40.

MARQUES, A.C. 2001. O gênero Eudendrium (Hydrozoa, Anthomedusae, Eudendriidae) no Brasil. Pap. Avulsos Zool. 41(22):329-405.

MARQUES, A.C. \& COLLINS, A.G. 2004. Cladistic analysis of Medusozoa and cnidarian evolution. Invertebr. Biol. 123(1):23-42.

MARQUES,A.C. \& MIGOTTO,A.E. 2001. Cladistics analysis and new classification of the family Tubulariidae (Hydrozoa, Anthomedusae). Pap. Avulsos Zool. 41(25):465-488.

MARQUES, A.C. \& OLIVEIRA, O.M.P. 2003. Eudendrium caraiuru n. sp. (Hydrozoa; Anthoathecata; Eudendriidae) from the southeastern coast of Brazil. Zootaxa. 307:1-12.

MASUNARI, S. \& FORNERIS, L. 1981. O ecossistema fitaluma revisão. In Seminários de Biologia Marinha, 1980. Academia Brasileira de Ciências, Rio de Janeiro. p.149-172.

MIGOTTO, A.E. 1993. Hidróides (Hydrozoa, Cnidaria) marinhos bentônicos da região costeira de São Sebastião, SP. Tese de doutorado, Instituto de Biociências, Universidade de São Paulo, São Paulo.

MIGOTTO, A.E. 1996. Benthic shallow-water hydroids (Cnidaria, Hydrozoa) of the coast of São Sebastião, Brazil, including a checklist of Brazilian hydroids. Zool. Verh. 306:3-125.

MIGOTTO, A. E. 1998. The life cycle of Sertularia marginata Kirchenpauer, 1864 (Cnidaria, Hydrozoa): a medusoidproducing sertulariid. J. Nat. Hist. 32: 1-12.

MigOTTO, A.E. \& MARQUES, A.C. 1999a. Hydroid and medusa stages of the new species Ectopleura obypa (Cnidaria: Hydrozoa: Tubulariidae) from Brazil. Proc. Biol. Soc. Wash. 112(2):303-312.

MIGOTTO, A.E. \& MARQUES, A.C. 1999b. Redescription of Dentitheca bidentata (Cnidaria: Hydrozoa, Plumulariidae), with notes on its life cycle. J. Nat. Hist. 33:949-960.

MIGOTTO,A.E. \& SILVEIRA, F.L. 1987. Hidróides (Cnidaria, Hydrozoa) do litoral sudeste e sul do Brasil: Halocordylidae, Tubulariidae e Corymorphidae. Iheringia, Zool. 66:95-115.

MIGOTTO, A.E., SILVEIRA, F.L., SCHLENZ, E. \& FREITAS, J.C. 1999. Cnidaria. In Biodiversidade do estado de São Paulo, Brasil. Invertebrados Marinhos (A.E. Migotto \& C.G. Tiago eds.). Fapesp, São Paulo. p.35-46. 
MILLARD, N.A.D. 1975. Monograph on the Hydroida of Southern Africa. Ann. S. Afr. Mus. 68:1-513.

OLIVEIRA, O.M.P. 2003. Diversidade e sazonalidade de hidróides (Cnidaria, Hydrozoa) epifíticos no canal de São Sebastião, SP. Dissertação de mestrado, Instituto de Biociências, Universidade de São Paulo, São Paulo.

OLIVEIRA, O.M.P., MARQUES,A.C. \& MIGOTTO,A.E. 2000. Morphometric patterns of two fouling Eudendrium spp. (Hydrozoa, Anthomedusae, Eudendriidae) from São Sebastião, SE Brazil. Braz.Arch. Biol. Techn. 43(5):519-526.

SILVEIRA, F.L. \& MIGOTTO, A.E. 1991. The variation of Halocordyle disticha (Cnidaria, Athecata) from the Brazilian coast: an environmental indicator species? Hydrobiologia. 216/217:422-437.

VAN ITEN, H., LEME, J.M., SIMÕES, M.G., MARQUES, A.C. \& COLLINS, A.G. 2006. Reassessment of the phylogenetic position of conulariids (?Vendian-Triassic) within the subphylum Medusozoa (phylum Cnidaria). J. Syst. Paleont.4(2):109-118.

Título: Chave de identificação dos hidróides (Cnidaria, Hydrozoa) epifíticos do Canal de São Sebastião (SE, Brasil).

Autores: Otto Müller Patrão de Oliveira, Antonio Carlos Marques \& Alvaro Esteves Migotto

Biota Neotropica, Vol. 6 ( number 2): 2006

http://www.biotaneotropica.org.br/v6n2/pt/ abstract?identification-key+bn02306022006

Recebido em 03/05/2005 - Revisado em 15/03/2006 Aceito e publicado em 11/05/2006.

ISSN 1676-0603

http://www.biotaneotropica.org.br 
Tabela 1. Quadro sinóptico da classificação dos hidróides epifíticos encontrados no Canal de São Sebastião.

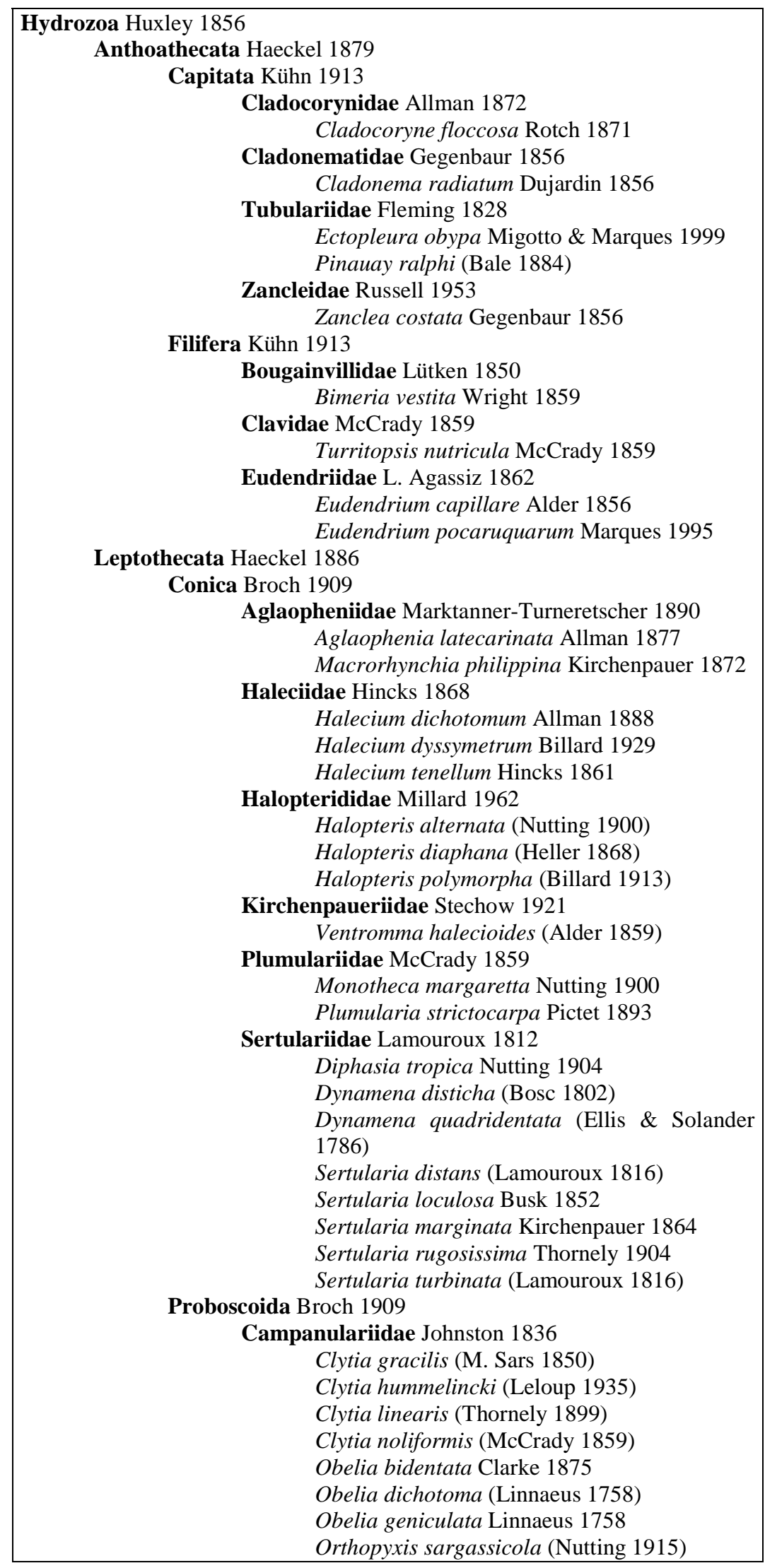

http://www.biotaneotropica.org.br 


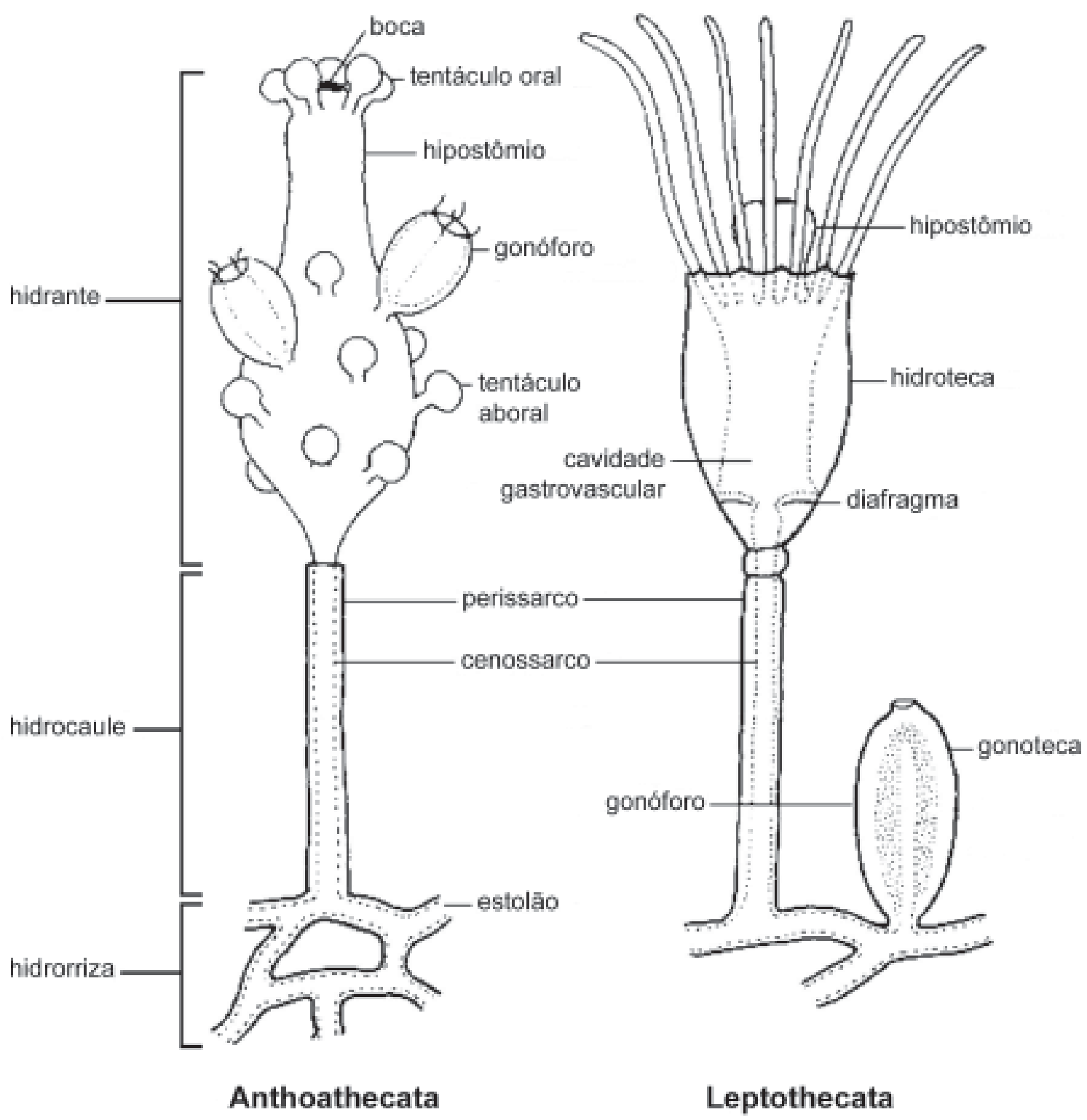

Figura 1. Representação esquemática de hidróides tecados e atecados, assinalando suas principais características morfológicas (modificado de Millard 1975). 

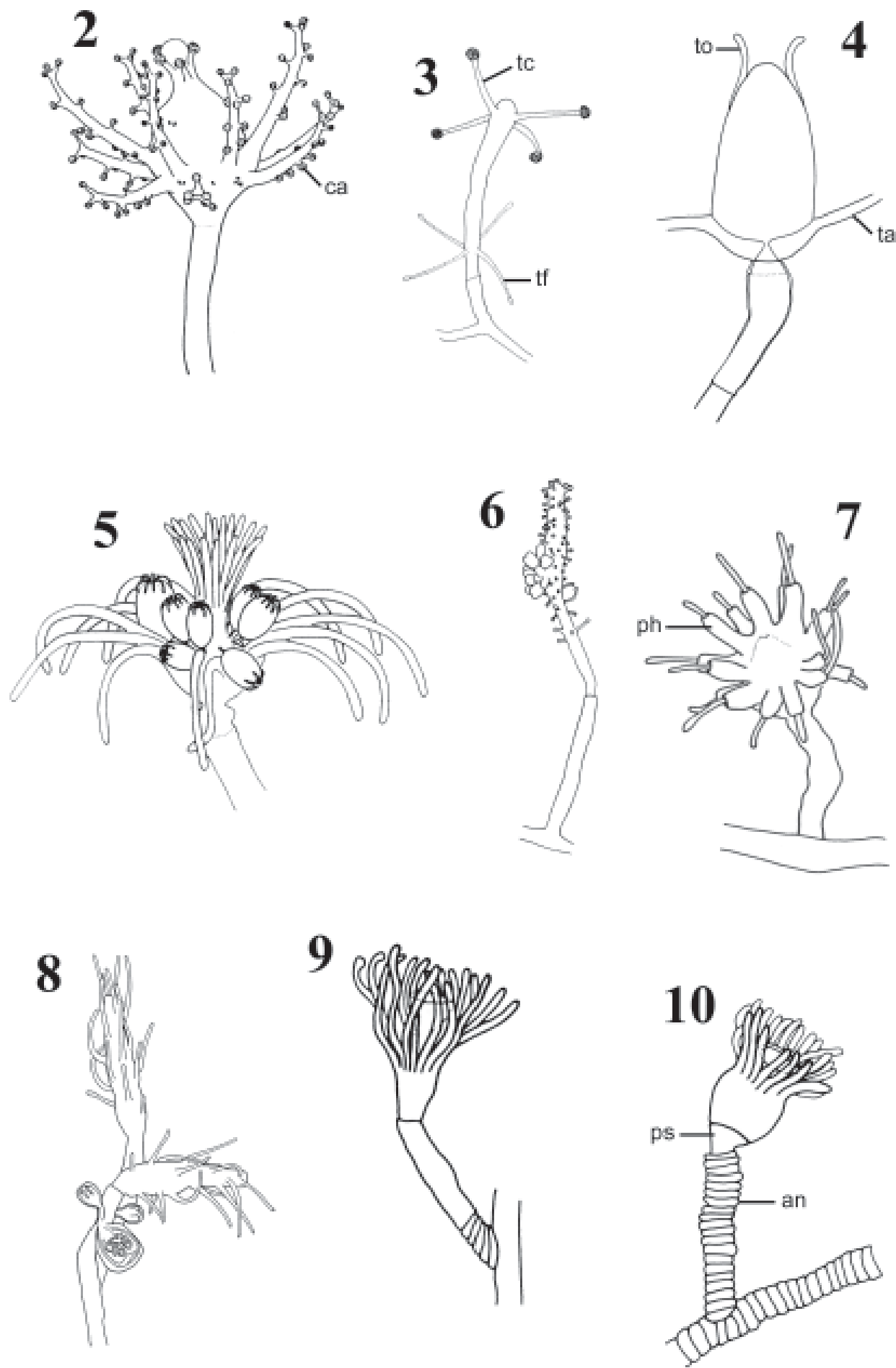

Figura 2. Cladocoryne floccosa Rotch 1871. Escala 500 $\mu$ m. ca, capítulo.

Figura 3. Cladonema radiatum Dujardin 1856. Escala $400 \mu m$. tc, tentáculo capitado; tf, tentáculo filiforme.

Figura 4. Ectopleura obypa Migotto \& Marques 1999. Escala 500 $\mu$ m. ta, tentáculo aboral; to, tentáculo oral.

Figura 5. Pinauay ralphi (Bale 1884). Escala $500 \mu \mathrm{m}$.

Figura 6. Zanclea costata Gegenbaur 1856. Escala 500mm.

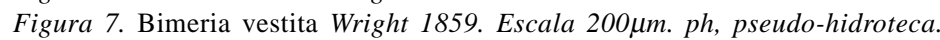

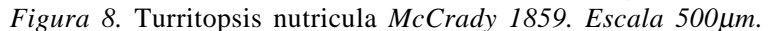

Figura 9. Eudendrium capillare Alder 1856. Escala 500 $\mu$ m.

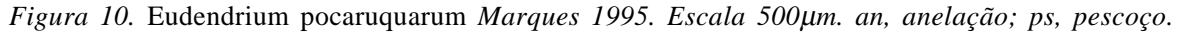

http://www.biotaneotropica.org.br 

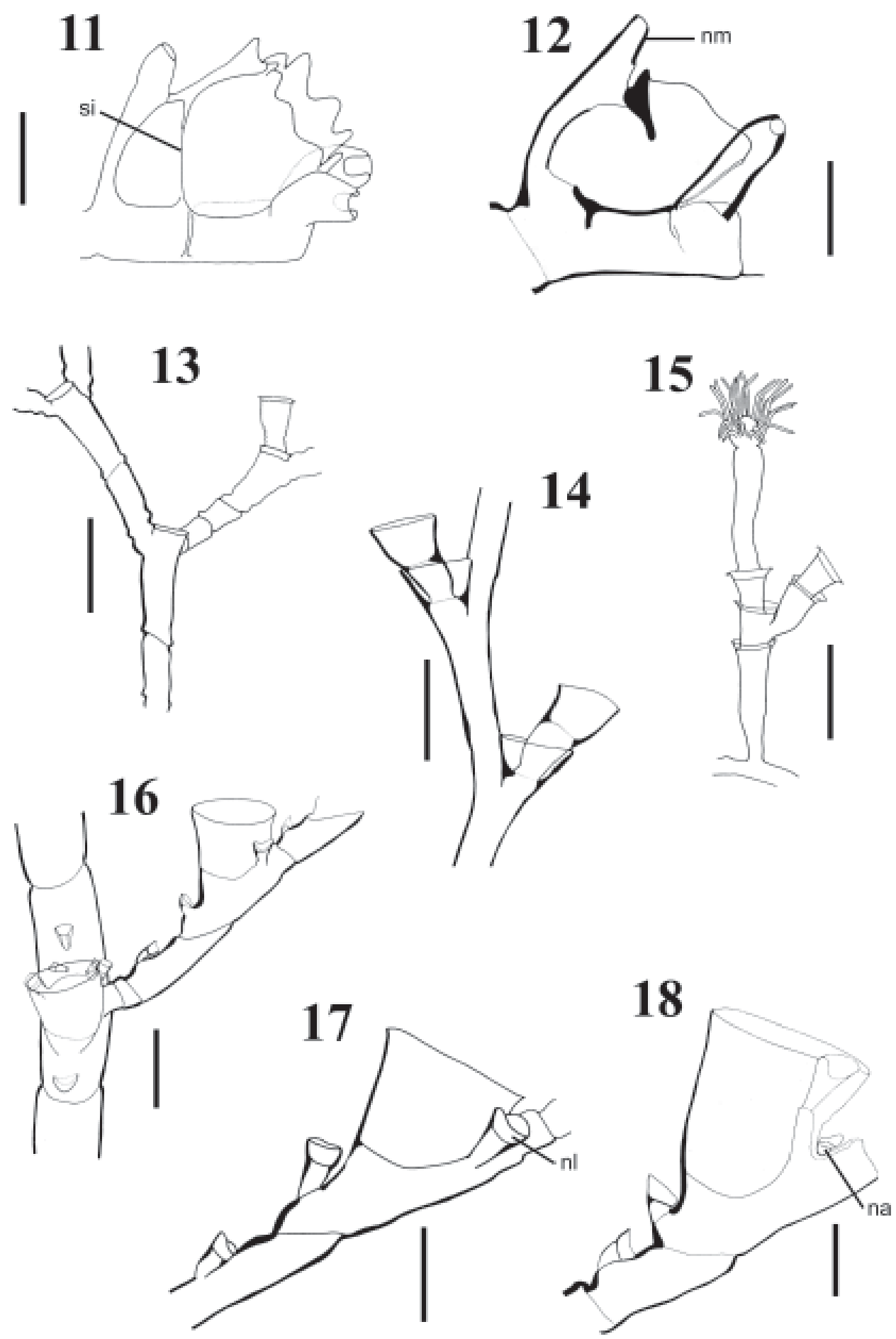

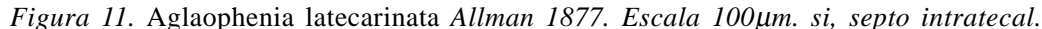

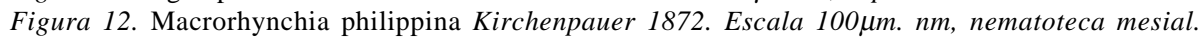

Figura 13. Halecium dichotomum Allman 1888. Escala $400 \mu \mathrm{m}$.

Figura 14. Halecium dyssymetrum Billard 1929. Escala $400 \mu \mathrm{m}$.

Figura 15. Halecium tenellum Hincks 1861. Escala 400 $\mu$ m.

Figura 16. Halopteris alternata (Nutting 1900). Escala 200 $\mu \mathrm{m}$.

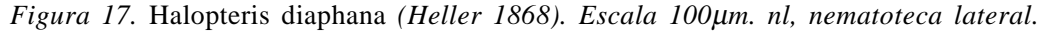

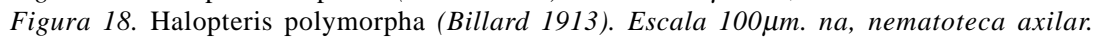



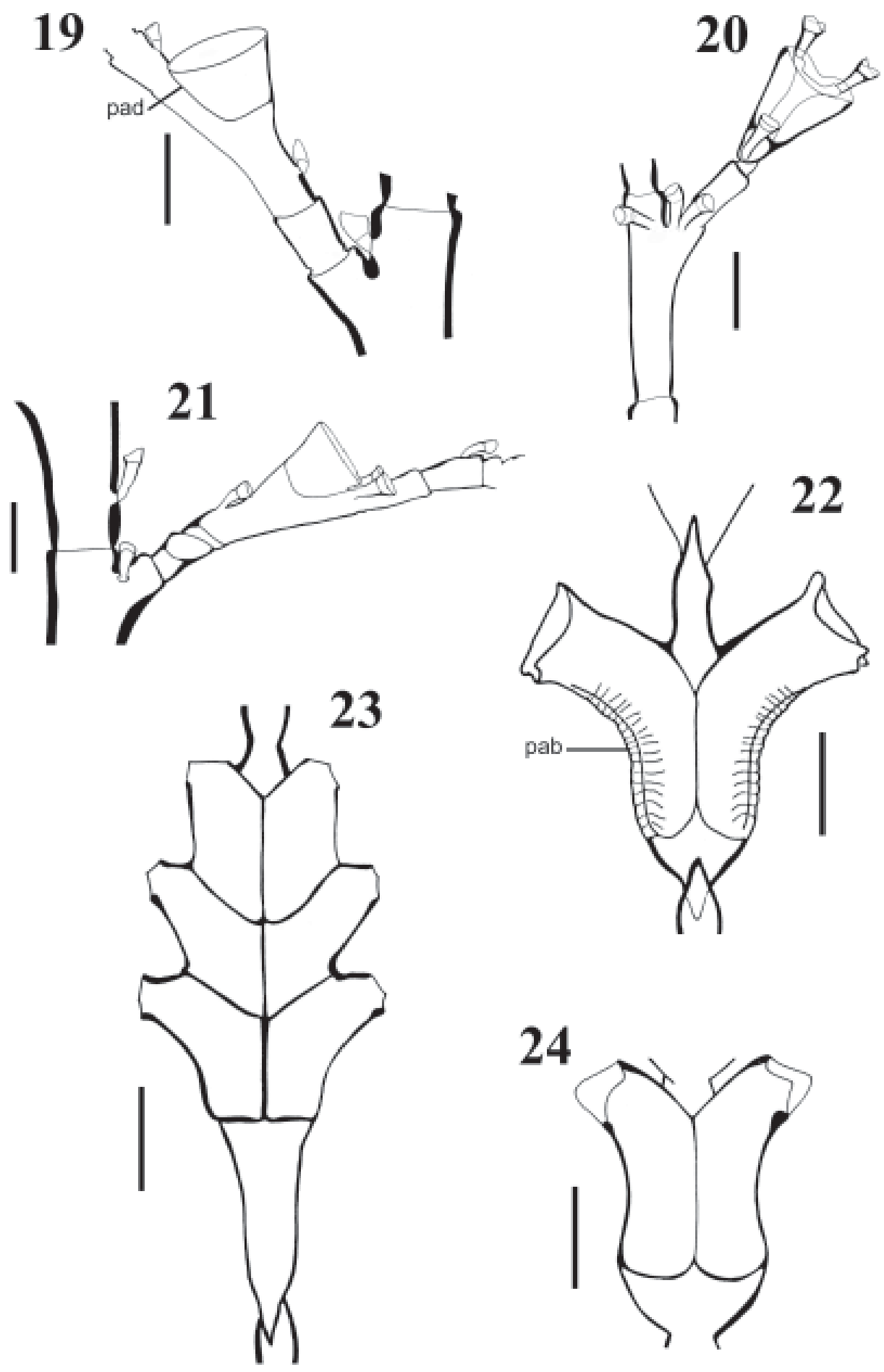

Figura 19. Ventromma halecioides (Alder 1859). Escala 100 $\mu$ m. pad, parede adcaulinar da hidroteca. Figura 20. Monotheca margaretta Nutting 1900. Escala 100 $\mu$ m.

Figura 21. Plumularia strictocarpa Pictet 1893. Escala $100 \mu \mathrm{m}$

Figura 22. Diphasia tropica Nutting 1904. Escala 200 $\mu \mathrm{m}$. pab, parede abcaulinar da hidroteca.

Figura 23. Dynamena quadridentata (Ellis \& Solander 1786). Escala $200 \mu m$.

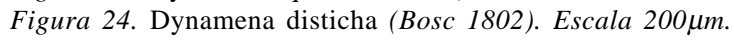



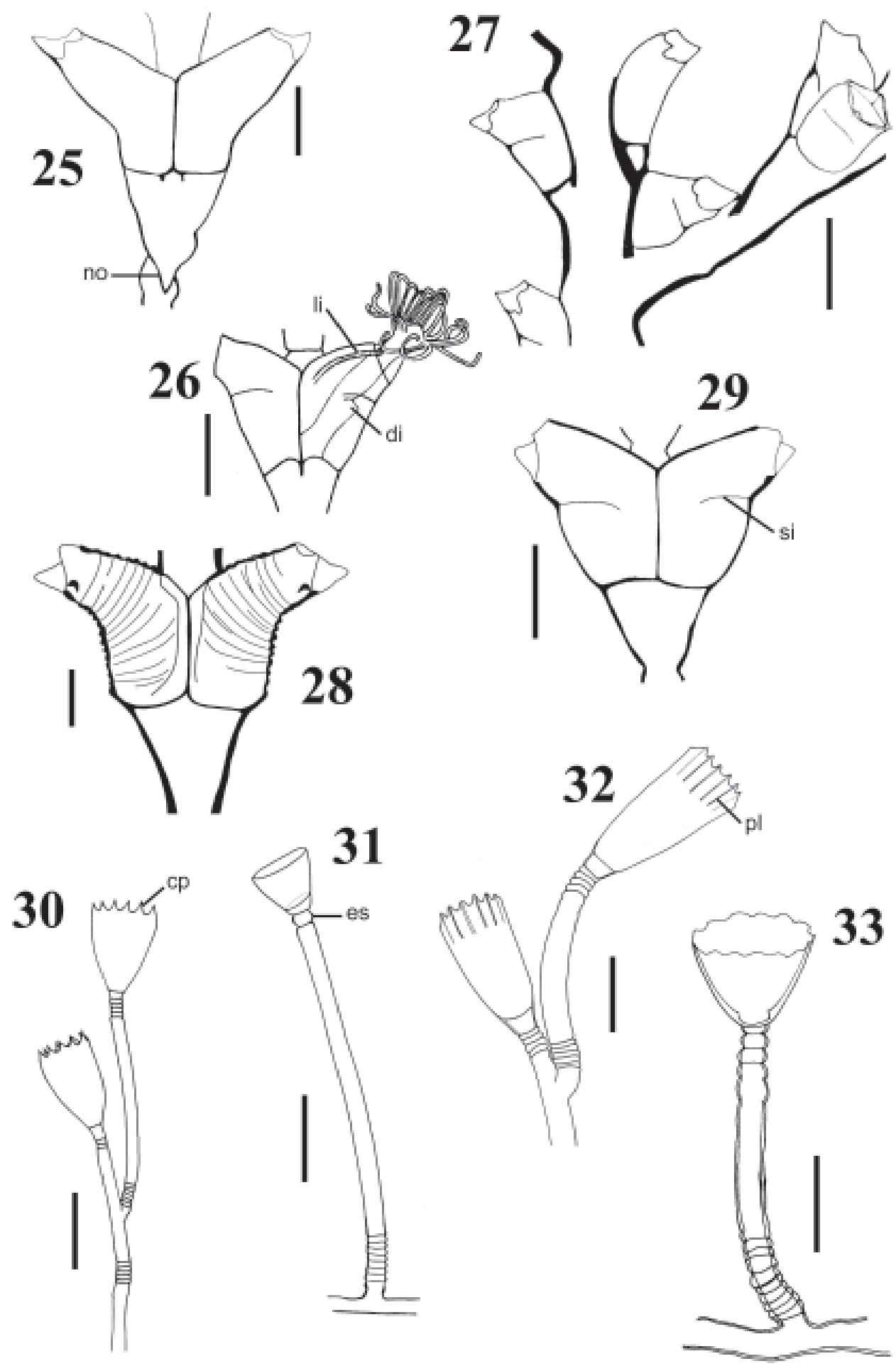

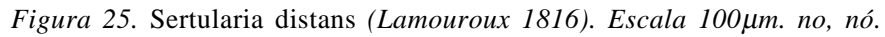

Figura 26. Sertularia loculosa Busk 1852. Escala $200 \mu \mathrm{m}$. di, divertículo; li, lígula.

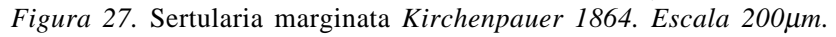

Figura 28. Sertularia rugosissima Thornely 1904. Escala 100 $\mu \mathrm{m}$.

Figura 29. Sertularia turbinata (Lamouroux 1816). Escala $200 \mu \mathrm{m}$. si, septo intratecal.

Figura 30. Clytia gracilis (M.Sars 1850). Escala 500 $\mu m$. cp, cúspide.

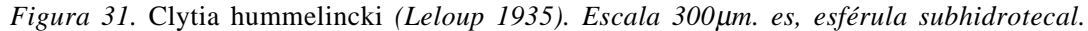

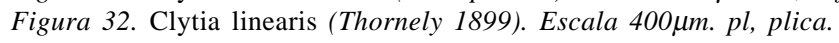

Figura 33. Clytia noliformis (McCrady 1859). Escala 300um.

http://www.biotaneotropica.org.br 

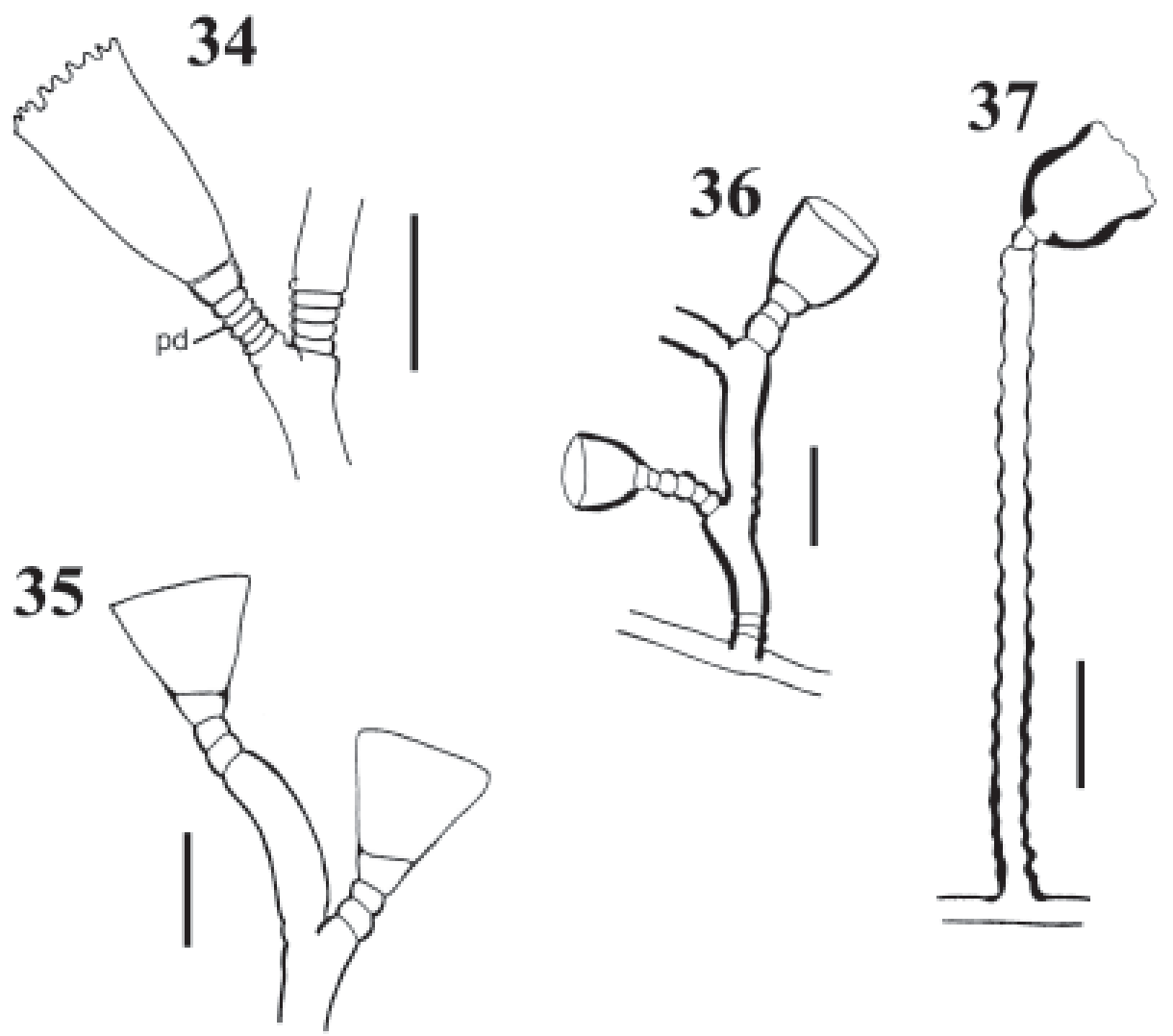

Figura 34. Obelia bidentata Clarke 1875. Escala 200um. pd, pedículo.

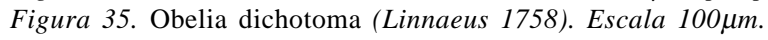

Figura 36. Obelia geniculata Linnaeus 1758. Escala 200 $\mu$ m.

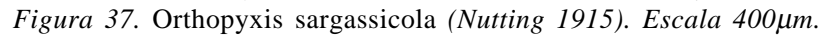

\section{Anexo 1 - Glossário.}

Abcaulinar: do lado oposto ao hidrocaule. (vide Figura 22.pab)

Aboral: em direção oposta ou do lado oposto à boca.

Actínula: estágio de desenvolvimento de alguns hidróides. Fase larval lecitotrófica, que lembra um pólipo. Comum nos tubulariídeos.

Adcaulinar: do lado contíguo ao hidrocaule. (vide Figura 19.pad)

Adnato: em contato com.

Alternado: diz-se de estruturas não diretamente opostas, que se alternam quanto ao ponto de origem em relação ao eixo longitudinal do crescimento.

Anelação: formação de anéis, constrições transversais consecutivas no perissarco. (vide Figura 10.an)

Apical: próximo ou em direção à extremidade livre.

Atecado: hidróide que não possui teca (envoltório de perissarco em torno do hidrante).

Blastóstilo: estrutura responsável pela produção de gonóforos.

Capitado: tentáculo com capítulo. (vide Figura 3.tc) 
Capítulo: concentração arredondada de nematocistos no tentáculo. (vide Figura 2.ca)

Cavidade gastrovascular: cavidade revestida por gastroderme, onde ocorre a digestão extracelular e por onde são transportadas substâncias para toda a colônia. (vide Figura 1)

Cenossarco: tecidos vivos de um hidróide, geralmente recobertos por perissarco. (vide Figura 1)

Claviforme: em forma de clava.

Cnida: Cápsula produzida intracelularmente, contendo um tubo enovelado capaz de se everter.

Colônia: organização modular na qual as diversas partes (no caso dos hidróides, os hidrantes e blastóstilos, por exemplo) estão interligados e são interdependentes.

Córbula: estrutura em forma de cesta, formada por hidrocládios modificados, que protege um ou mais gonângios.

Coroa de tentáculos: conjunto de tentáculos dispostos de forma circular ao redor do hidrante.

Cúspides: projeções pontiagudas na margem da hidroteca. (vide Figura 30.cp)

Diafragma: projeção interna da parede da hidroteca, na altura da base do hidrante. (vide Figura 1)

Dicotomia: divisão da região terminal em duas partes iguais.

Divertículo: dobra na parede da coluna do hidrante de certos hidróides, dos sertulariídeos por exemplo, visível quando estes estão contraídos. (vide Figura 26.di)

Esférula sub-hidrotecal: anelação mais distal do pedículo, de forma arredondada, presente em algumas espécies, que confere articulação entre à hidroteca e o pedículo. (vide Figura 31.es)

Estolão: porção da hidrorriza, fixa ao substrato, que interliga módulos da colônia. (vide Figura 1)

Estolonal: modo de crescimento no qual os hidrantes surgem diretamente do estolão, que geralmente forma uma rede de tubos aderida ao substrato.

Euritelo: tipo de nematocisto que apresenta um alargamento no ápice da porção basal espessada do túbulo ("shaft”), anterior à região do filamento.

Filatocarpo: hidrocládio curvado, provido de nematotecas, que protege os gonângios.

Filiforme: tentáculo com distribuição uniforme de nematocistos. (vide Figura 3.tf)

Gastrozoóide: pólipo especializado em capturar e digerir o alimento.

Gonóforo: estrutura de crescimento lateral em relação ao pólipo que possui gônadas quando madura. (vide Figura 1)

Gonoteca: envoltório de perissarco que protege o gonozoóide em hidróides tecados. (vide Figura 1)

Gonozoóide: pólipo especializado para a reprodução.

Hidrante: pólipo com função alimentar (= gastrozoóide). (vide Figura 1)

Hidrocaule: porção ereta da colônia, que surge da hidrorriza e porta hidrante(s). (vide Figura 1)

Hidrocládio: ramo lateral do hidrocaule.

Hidróide: fase polipóide de cnidários hidrozoários das classes Anthoathecata e Leptothecata.

Hidrorriza: conjunto de tubos responsáveis pela fixação do hidróide ao substrato. (vide Figura 1)

Hidroteca: expansão do perissarco dos hidróides Leptothecata que protege o hidrante. (vide Figura 1)

Hipostômio: porção terminal do hidrante, bem diferenciada em alguns hidróides, que porta a boca. (vide Figura 1)

Internódio: segmento do hidrocaule ou hidrocládio limitado por constrições ou nós.

http://www.biotaneotropica.org.br 
Lígula: estrutura em forma de língua, armada com nematocistos, presente no hidrante de Sertularia loculosa. (vide Figura 26.li)

Mastigóforo: tipo de nematocisto cuja base alargada do túbulo ("shaft”) apresenta diâmetro homogêneo.

Medusa: fase sexuada, de vida livre, no ciclo de vida dos cnidários Medusozoa.

Monossifônico: hidrocaule composto por um único tubo (= afasciculado).

Nematocisto: tipo de cnida, com capacidade de perfurar e injetar substâncias urticantes nas presas dos cnidários, ou de envolvê-las.

Nematóforo: estrutura defensiva, armada com nematocistos.

Nematoteca: expansão do perissarco que envolve o nematóforo.

Nematoteca axilar: nematoteca posicionada abaixo da parede adcaulinar da hidroteca de alguns halopteridídeos. (vide Figura 18.na)

Nematoteca lateral: nematoteca posicionada lateralmente à hidroteca. (vide Figura 17.nl)

Nematoteca mesial: nematoteca posicionada próxima ou adnata à parede abcaulinar da hidroteca. (vide Figura 12.nm)

Nó: projeção interna do perissarco na área de ligação dos internódios. (vide Figura 25.no)

Opérculo: estrutura composta por uma ou várias valvas de perissarco que atua como uma tampa para a hidroteca.

Oposto: diz-se de estruturas diretamente opostas, cujos pontos de origem se localizam na mesma altura em relação ao eixo longitudinal do crescimento.

Oral: diz-se de estruturas próximas à região onde se localiza a boca.

Pedicelado: Hidrante não séssil, isto é, ligado por um pedículo aos ramos principal ou secundários do hidrocaule.

Pedículo: haste que sustenta um hidrante ou hidroteca terminal e geralmente confere capacidade de movimentação ao hidrante/hidroteca. (vide Figura 34.pd)

Perissarco: porção externa quitinosa, secretada pela epiderme, que reveste o cenossarco do hidróide.

Pescoço: parte basal do hidrante, ligada ao pedículo, geralmente exposta nos hidróides atecados. (vide Figura 10.ps)

Plica: dobra fina, longitudinal, presente em certa extensão, na parede da hidroteca. (vide Figura 32.pl)

Plicado: hidroteca apresentando plicas.

Pólipo: fase séssil do ciclo de vida dos cnidários.

Polissifônico: hidrocaule composto por dois ou mais tubos (= fasciculado).

Pseudo-hidroteca: envoltório membranoso ou gelatinoso ao redor dos hidrantes de alguns atecados. (vide Figura 7.ph)

Septo intratecal: projeções transversais de perissarco no interior da hidroteca. (vide Figuras 11 e 29.si)

Tecado: hidróide que possui envoltório de perissarco (hidroteca) em torno do hidrante.

Tentáculo: projeção digitiforme do hidrante, geralmente com nematocistos, utilizada para defesa, captura e manipulação das presas. (vide Figura 1)

Tricotomia: divisão da porção terminal em três partes.

Valva: estrutura do perissarco que compõe o opérculo da hidroteca em alguns hidróides.

Vasiforme: em forma de vaso, com uma expansão na parte basal seguido de um afunilamento e nova expansão na parte distal.

http://www.biotaneotropica.org.br 